ДОМБРОВСКАЯ Анна Юрьевна - доктор социологических наук, профессор департамента политологии факультета социальных наук и массовых коммуникаций, главный научный сотрудник центра политических исследований Финансового университета при Правительстве РФ (125993, Россия, г. Москва, ГСП-3, Ленинградский пр-кт, 49; an-doc@yandex.ru)

\title{
МЕТОДОЛОГИЯ И МЕТОДИКА АНАЛИЗА ОНЛАЙН-СЕТЕВОГО БРЕНДА ВУЗОВ В СИСТЕМЕ СРЕДСТВ ИНФОРМАЦИОННОГО ВОЗДЕЙСТВИЯ НА ОБЩЕСТВЕННОЕ СОЗНАНИЕ
}

\begin{abstract}
Аннотация. Статья нацелена на апробацию в среде исследователей-эмпириков методологических и методических разработок, фундирующих прикладной анализ эффектов онлайн-сетевого брендирования университетов. Перед исследованием авторы обосновывают выбор концепций и подходов, способных обеспечить максимально объективное и всестороннее изучение характеристик социально-медийного имиджа университетов, предлагают дизайн эмпирического анализа, показывают возможные стратегии сэмплирования. Статья направлена на формирование экспертной дискуссии для совершенствования методологической и методической базы прикладного изучения онлайн-сетевого брендинга университетов в системе средств информационного воздействия на общественное сознание.

Ключевые слова: бренд университета, онлайн-сетевой имидж, социально-медийный поток, интеллектуальный поиск цифровых маркеров, аналитика социальных сетей, социальные графы

Статья подготовлена по результатам исследований, выполненныхза счет бюджетных средств по государственному заданию Финуниверситету.
\end{abstract}

B ажным средством воздействия на сознание и поведение граждан служит продвижение организационного бренда в социальных медиа. Вузам мониторинг характеристик их онлайн-бренда необходим для измерения эффективности влияния на целевую аудиторию, замера уровня лояльности к университетскому бренду.

Одним из наиболее актуальных и продуктивных направлений междисциплинарного знания, подходы, методы и инструменты которого позволяют решать подобные задачи, является социальный компьютинг - междисциплинарная область исследований, использующая возможности вычислительных систем для изучения социального поведения. Цель настоящего исследования - обосновать методологию и методику социально-медийного анализа онлайнбренда вузов на основе одного из методов социального компьютинга - Predictor Mining (интеллектуальный поиск цифровых маркеров изучаемого предмета).

Повышенное внимание к онлайн-маркерам исследуемых предметов, т.е. их проявлениям в интернет-ресурсах, вызвано совокупностью причин. Ключевая причина состоит в том, что Интернет представляет уникальную среду для изучения поведения пользователей, их установок и мнений, в которой вычислительные системы и информационные технологии являются как средством извлечения знаний, так и средством создания и воспроизводства социального контекста.

Predictor Mining, осуществляемый с помощью специального программного обеспечения (например, сервисы для мониторинга социальных медиа), позволяет аккумулировать элементы информационного поля (документ, текст, изображение, видеозапись), имеющие отношение к исследуемому предмету (вос- 
приятие онлайн-бренда вуза). Необходимо сформировать некоторый набор маркеров, т.е. небольших связных элементов (слова, выражения, изображения и т.д.), идентифицирующих принадлежность объекта к исследуемой предметной области, т.е. речевых паттернов, репрезентация которых в интернет-контенте делает его релевантным предмету анализа.

Среди относительно небольшого числа отечественных исследовательских работ об изучении бренда вуза доминируют труды, нацеленные на изучение представленности, упоминаемости вузов в традиционных и новых медиа [Петруша 2018; Косарева 2013; Шевченко, Локтюшина 2014].

Исследовательские работы зарубежных авторов следует разделить на несколько групп. Первая из них - группа публикаций об анализе потребительских стратегий [Блэкуэлл, Миниард, Энджел 2007; Говард, Шет 2001]. Вторая группа аналитических трудов сконцентрирована на методах изучения лидеров мнения - агентах онлайн-сетевого маркетинга [Freberg et al. 2011; Pang et al. 2016; Kalb 2013; Hausman 2012; Ryan, Jones 2012]. Стоит отметить и ряд наиболее известных зарубежных работ по онлайн-брендированию [Аакер 2003; Джоунс 2005; Дойль 2003; Капферер 2007; Керби, Марсден 2007; Котлер, Келлер 2008].

Исходя из приведенных данных о разработанности в отечественной и зарубежной литературе проблематики социально-медийного анализа и управления брендом университета онлайн, отметим, что существует явный дефицит научных исследований, сфокусированных на возможностях интеллектуального поиска цифровых маркеров Predictor Mining как основе социально-медийного анализа в изучении эффективности продвижения бренда университетов в онлайн-сетевой среде. При доминировании общих трудов о технологиях брендирования и узкопрофильных работ по копирайтингу в процессе формирования бренда фактически нераскрытым остается предметное поле автоматизированного анализа онлайн-сетевого контента университетов, измерения вовлеченности российских пользователей в информационные потоки о вузах, выявления степени лояльности пользователей университетскому бренду, изучения плотности и силы связей в вузовских цифровых сообществах.

Для решения этих исследовательских вопросов требуется применение комплексной методологии, сочетающей несколько подходов. Основные положения социального конструкционизма позволяют рассматривать социальномедийное пространство как среду формирования образа университета, необходимых характеристик восприятия вуза в сознании пользователей, а также как инструмент влияния на состояние системы идентичностей абитуриентов, студентов, выпускников, всех целевых аудиторий университета.

Структурный функционализм обеспечивает методологическую основу для выявления эффектов онлайн-сетевых потоков, таргетированных на целевые группы вуза.

Анализ структуры сети (mapping network) предполагает исследование позиций, которые занимают акторы (в нашем случае - инфлюенсеры университета, лидеры мнений в социальных медиа, аффилированные с университетом), и отношений между этими позициями.

Для решения задач математического моделирования в условиях неопределенности знаний и получения вероятностного вывода в таких моделях в последние четверть века широко используются вероятностные графические модели (ВГМ), в частности байесовские сети.

Базовым направлением анализа в рамках выступает сегментирование цифровой целевой аудитории - процесс идентификации целевой аудитории в социальных медиа и разделение ее представителей на группы с общими соци- 
альными характеристиками, ее социальная профилизация. Сегментация целевой аудитории в процессе брендирования университета позволяет выявить особенности потребностей различных таргетных групп, их ценности и установки. Сегментационный анализ также обеспечивает возможность определения таких направлений образовательных услуг, конкуренция в которых имеет низкий уровень. Продвижение этих направлений среди сегментов целевой аудитории может служить мощным инструментом формирования эффективного бренда вуза.

Предлагаемая эмпирическая модель исследования построена на сочетании методов, относящихся к количественной (киберметрия стихийных и целенаправленных информационных потоков в социальных медиа, анализ графов социальных сетей) и качественной (когнитивное картирование социальномедийных документов) стратегиях прикладного анализа. Количественные методы направлены на получение эмпирических данных о структурных характеристиках онлайн-бренда университетов; качественные методы ориентированы на изучение содержательных характеристик формируемого социальномедийного имиджа вузов, ценностей и смыслов, адресованных целевой аудитории университетов в традиционных СМИ и новых медиа.

Сочетание количественных и качественных, онлайновых и офлайновых, опросных и контент-аналитических методов обеспечит всестороннее, комплексное изучение предмета исследования, проверку гипотез разными методами сбора и анализа информации.

Формирование выборочной совокупности когнитивного картирования документов социальных медиа, составляющих потоки информации об университетах, подчиняется принципу репрезентации основных онлайн-сетевых каналов распространения информации о вузах и хронологическому принципу, обеспечивающему каждому релевантному документу равные шансы быть включенным в выборку исследования. При организационной сложности реализации отбора по принципу собственно случайной выборки, требующей создания нумерованного списка генеральной совокупности, наиболее универсальной технологией отбора материалов служит адаптированная к качественному анализу социальномедийных документов методика механического отбора документов по установленному хронологическому принципу (начальная, срединная, последняя неделя каждого месяца/сезона/года в зависимости от хронологических рамок исследования и размера выборочной совокупности исследования). Внутри обоснованных периодов применяется принцип сплошного анализа. Ключевыми параметрами в ходе когнитивного картирования служат: тематическая направленность, модальность изучаемых материалов, речевые приемы формирования дискурсов, их контексты, характеристики пользовательской активности. Этот качественный срез анализа дополняется количественной стратегией: выявленные содержательные характеристики квантифицируются, т.е. подсчитывается частота их встречаемости. В ходе последующей обработки этих данных в программе SPSS Statistics возможно установление значимых корреляций между значениями указанных переменных. Эти результаты обеспечат понимание признаков информационных материалов об университете, способствующих получению желаемых эффектов, увеличению степени лояльности к бренду вуза. Не менее существенным итогом когнитивного картирования как в первую очередь метода, работающего со смыслами, является формирование словаря цифровых маркеров - слов и словосочетаний в социально-медийных документах, отражающих ту или иную грань онлайн-бренда университета. Каждая грань/контекст цифровых маркеров служит основой для сегментирования информационных потоков о вузах. Такое сегментирирование позволяет осуществлять автоматизированное сопоставле- 
ние содержательных и структурных характеристик разных потоков об университете между собой или потоков о разных вузах.

Для автоматизированной выгрузки релевантного массива данных (на основе разработанного словаря маркеров) необходимо применять сервисы для мониторинга социальных сетей, способных аккумулировать не менее 1 млн сообщений из наиболее популярных в изучаемом национальном сегменте социальных медиа (как правило, 30 блогохостингов и сетей). Аналитические опции сервисов позволяют получить данные о динамике информационных потоков, связанных с вузами, степени вовлеченности в эти потоки целевых аудиторий, их социально-демографические характеристики, определить контекстуальное поле потоков, модальность, каналы распространения информации, эффективность данных каналов в формировании онлайн-бренда университетов.

Взаимосвязи внутри пользователей цифровых групп университета и между ними изучаются с помощью метода анализа цифровой инфраструктуры и социальных графов (плотность связей между участниками релевантных социально-медийных сообществ). Для получения надежных результатов необходимо построить не менее 20 социальных графов онлайн-сетевых групп каждого вуза - исследовательского кейса. Программное обеспечение для реализации этого метода разрабатывается как приложение к исследуемым блогохостингам, социальным сетям.

Резюмируя итоги обоснования методологической основы изучения эффектов онлайн-сетевого брендирования университетов, отметим, что данные исследования чаще всего проводятся на уровне общей интуиции с использованием примитивного инструмента и ограничиваются получением частотного распределения упоминаемости вузов в социальных медиа и структурой тональности документов, содержащих название исследуемых университетов. Вместе с тем задачи анализа эффективности онлайн-бренда, факторов повышения лояльности к бренду, смыслов и контекстов, конструирующих образ университетов в социальных медиа, требует применения комплексного подхода к обоснованию исследовательского дизайна.

Социально-конструкционистский, структурно-функциональный и аналитико-сетевой типы базиса исследования онлайн-бренда вузов обеспечивают возможность изучения следующих эмпирических модулей: вовлеченность целевой аудитории в информационные потоки об университетах; лояльность таргетных групп бренду вузов; семантическое ядро и смыслы о качестве брендов, циркулирующие в цифровой среде; плотность и сила связей в цифровых сообществах, осуществляющих брендинг Финансового университета онлайн, пересечение аудиторий данных онлайн-групп. Эти направления исследования реализуются с помощью гибридного эмпирического дизайна, включающего качественный этап работы с документами для обоснования цифровых маркеров как основы сегментирования релевантных информационных потоков; автоматизированную социально-медийную аналитику, ориентированную на содержательные и структурные характеристики аккумулированных потоков, и анализ социальных графов как отражение силы и плотности взаимосвязей инфлюенсеров, лидеров мнений и представителей целевых аудиторий университетов в социальных медиа.

\section{Список литературы}

Аакер Д. 2003. Создание сильных брендов. М. Издательский дом Гребенникова. $340 \mathrm{c}$.

Блэкуэлл Р., Миниард П., Энджел Дж. 2007. Поведение потребителей. 10-е изд. СПб: Питер; ОАО «Техническая книга». 943 с. 
Говард Дж., Шет Дж. 2001. Теория поведения покупателя: Классики маркетинга. СПб: Питер. 180 с.

Джоунс Дж. 2005. Роль рекламы в создании сильных брендов. М.: Вильямс. 210 с.

Дойль П. 2003. Маркетинг-менеджмент и стратегии. СПб: Питер. 544 с.

Капферер Ж.-Н. 2007. Бренд навсегда: создание, развитие, поддержка ценности бренда. М.: Вершина. 448 с.

Керби Дж., Марсден П. 2007. Маркетинг «из уст в уста»: вирусный, «сарафанный» и маркетинг разговоров. М.: Вершина. 447 с.

Косарева О.Е. 2013. Использование социальных медиа как источника информации для анализа имиджа вуза. - Вестник ОрелГИЭТ. № 3(25). С. 69-74.

Котлер Ф., Келлер К.Л. 2008. Маркетинг менеджмент. 12-е изд. СПб: Питер. 303 с.

Петруша П.Г. 2018. Оценка известности брендов российских университетов на международном рынке образования с использованием метрик социальных сетей. - Политический маркетинг. № 6(256). С. 3-11.

Шевченко Д.А., Локтюшина Ю.В. 2014. Эффективность веб-сайтов высших учебных заведений. Методика оценки конкурентоспособности сайта вуза в интернете. М.: ННОУ-МИПК. $141 \mathrm{c}$.

Freberg K., McGaughey K., Graham K., Freberg L.A. 2011. Who Are the Social Media Influencers? A Study of Public Perceptions of Personality. - Public Relations Review. Vol. 37. Is. 1. P. 90-92.

Hausman A. 2012. 5 Tools for Optimizing Your Social Media Strategy Post Penguin. URL: https://www.hausmanmarketingletter.com/5-tools-for-optimizingyour-social-media-strategy-post-penguin/ (accessed 29.09.2021).

Kalb I. 2013. 8 Steps to Creating an Effective Marketing Information System. URL: https://www.businessinsider.com/the-marketing-information-system-the-missinglink-for-greater-success-2013-11 (accessed 26.09.2021).

Pang A., Yingzhi Tan E., Song-Qi Lim R. et al. 2016. Social Media Influencers in Singapore. - Media Asia. Vol. 43. No. 1. P. 56-68.

Ryan D., Jones C. 2012. Understanding Digital Marketing: Marketing Strategies for Engaging the Digital Generation. Kogan Page. 288 p.

DOMBROVSKAYA Anna Yur'evna, Dr.Sci. (Soc.), Professor of the Department of Political Science, Faculty of Social Sciences and Mass Communications, Senior Research Fellow at the Center for Political Studies, Financial University under the Government of the Russian Federation (49 Leningradsky Ave, GSP-3, Moscow, Russia, 125993; an-doc@yandex.ru)

\section{METHODOLOGY OF ANALYSIS OF ONLINE NETWORK BRAND OF UNIVERSITIES IN THE SYSTEM OF INFORMATION IMPACT ON PUBLIC CONSCIOUSNESS}

\footnotetext{
Abstract. The article is focused on the approbation of methodological basis that underpin the analysis of the universities online network branding effects among empiricists. Before the upcoming research, the authors substantiate the choice of concepts and approaches that can provide the most objective and comprehensive study of the characteristics of the social media image of universities, propose an empirical analysis design, and show possible sampling strategies. The article is aimed at forming an expert discussion to improve the methodological framework of the applied study of online network branding of universities in the system of means of informational influence on public consciousness.

Keywords: university brand, online network image, social media flow, intelligent search for digital markers, social networks analysis, social graphs
} 